\title{
Technological pedagogical content knowledge in South African mathematics classrooms: A secondary analysis of SITES 2006 data
}

\author{
Authors: \\ Verona Leendertz ${ }^{1}$ \\ A. Seugnet Blignaut ${ }^{1}$ \\ Hercules D. Nieuwoudt ${ }^{1}$ \\ Christo J. Els ${ }^{2}$ \\ Suria M. Ellis ${ }^{3}$

\section{Affiliations:} \\ ${ }^{1}$ School of Natural \\ Science and Technology \\ for Education, Faculty \\ of Education Sciences, \\ North-West University, \\ Potchefstroom campus, \\ South Africa \\ ${ }^{2}$ School of Human Science, \\ Faculty of Education \\ Sciences, North-West \\ University, Potchefstroom \\ campus, South Africa \\ ${ }^{3}$ Department of Statistical \\ Consultation Services, \\ North-West University, \\ Potchefstroom campus, \\ South Africa

\section{Correspondence to:} \\ Seugnet Blignaut \\ Email: \\ seugnet.blignaut@nwu.ac.za

\section{Postal address:} \\ Private Bag X6001, \\ Potchefstroom 2520, \\ South Africa

\section{Dates:} \\ Received: 16 May 2013 \\ Accepted: 27 Nov. 2013 \\ Published: 11 Dec. 2013 \\ How to cite this article: \\ Leendertz, V., Blignaut, \\ A.S., Nieuwoudt, H.D., Els, \\ C.J., \& Ellis, S.M. (2013). \\ Technological pedagogical \\ content knowledge in \\ South African mathematics \\ classrooms: A secondary \\ analysis of SITES 2006 data. \\ Pythagoras, 34(2), Art. \\ \#232, 9 pages. http://dx.doi. \\ org/10.4102/pythagoras. \\ v34i2.232

\section{Read online:}

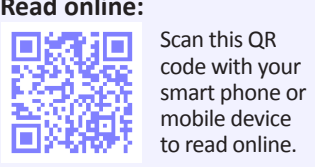

This article reports on a secondary data analysis conducted on the South African mathematics teachers' dataset of the Second Information Technology in Education Study (SITES 2006). The sample consisted of a stratified sample of 640 mathematics teachers from 504 randomly selected computer-using and non-computer-using schools that completed the SITES 2006 teachers' questionnaire, which investigated their pedagogical use of Information Communication Technology (ICT). The purpose of the current investigation was to investigate the level of Technological Pedagogical Content Knowledge (TPACK) of mathematics teachers, and how TPACK attributes contribute towards more effective Grade 8 mathematics teaching in South African schools, using the TPACK conceptual framework. The findings are presented according to the three clusters identified through the association between the main variables of the TPACK model and other variables on the SITES 2006 teachers' questionnaire: (1) impact of ICT use, (2) teacher practices and (3) barriers. A Cramér V of between 0.3 and 0.4 was considered to signal a medium effect that tended towards practically significant association, and a Cramér V of 0.4 or larger was considered to signal a large effect with practically significant association. The results indicate that the TPACK of mathematics teachers contributes towards more effective Grade 8 mathematics teaching in South African schools.

\section{Orientation and research problem}

Education in South Africa is constantly transforming according to the Department of Education requirements, such as the development of 21st century learning outcomes which allow learners to use information in different contexts (Department of Education [DOE], 2002; Law \& Chow, 2008b). Mathematics teaching is an indispensable part of the curriculum and fulfils an important role in the development of higher order thinking skills to accomplish specific tasks for the achievement of relevant pedagogical outcomes, conceptualisation, abstraction, generalisation, problem solving and information processing (Nieuwoudt \& Golightly, 2006). Mathematics teaching aims to develop learners to (1) have an acute awareness of how mathematical relationships are used in social, environmental, cultural and economic relations; (2) foster a love of mathematics; (2) recognise that mathematics is a creative part of human activity; (4) obtain profound theoretical understandings in order to make sense of mathematics; and (5) apply mathematics in physical, social and mathematical problems (DOE, 2002). The use of Information and Communication Technology (ICT) provides scaffolding for the socio-economic development and building of much needed skills in a newly industrialised country (Marais, 2009). ICT has become the mode of choice of communication amongst people in all spheres and its use in South African education increases daily (DOE, 2004). ICT supplements, supports and facilitates curricula (Ertmer, Addison, Lane, Ross \& Woods, 1999). Mathematics curriculum outcomes can be addressed through various ICTdriven activities: to perform calculations efficiently and to the required degree of accuracy, from describing patterns and relationships in the foundation phase to following laws and meanings of exponents in the senior phases (DOE, 2002; McDonald, 1988). ICT provides teachers with opportunities to assist in their teaching practices, to develop mathematical knowledge and skills, and to interact with learners, parents, peers, colleagues and the global society (Haddad \& Draxler, 2002). Although many mathematics teachers acknowledge the value of ICT in teaching and learning, the pedagogical use of ICT in South African schools remains dismally limited (Law \& Chow, 2008a).

The Second Information and Technology in Education Study (SITES) 2006, the most recent in the series of ICT use in education studies conducted by the International Association for the Evaluation of Educational Achievement, investigated the pedagogical use of ICT across the world. South Africa performed poorly in the integration of ICT into teaching and learning practices (Law

Copyright: (C) 2013. The Authors. Licensee: AOSIS OpenJournals. This work is licensed under the Creative Commons Attribution License. 
\& Chow, 2008a). Even though ICT infrastructure in schools for teaching and learning has more than doubled, from $12.3 \%$ in 1999, to 26.5\% in 2002 (DOE, 2004) and 38\% in 2007 (DOE, 2007), the situation is not conducive for integration at all levels of education. The e-Education White Paper stipulates a three-phase plan to have a fully integrated ICT system in all spheres of education, administration, management and teaching and learning, by 2013 (DOE, 2004). However, as the stance of mathematics teaching and learning is a muchdebated issue and concern in South African schools (Prew, 2013), role players in education have to take notice of the findings from SITES 2006 if we want an ICT-integrated and competitive education system. However, merely introducing ICT into teaching and learning is not sufficient to ensure its effective use for teaching and learning. Teachers should be competent with sufficient TPACK in order to adequately integrate ICT into their pedagogical practices (Mishra \& Koehler, 2006).

This article poses the question: To what extent does TPACK contribute towards more effective Grade 8 mathematics teaching in South African schools?

\section{Theoretical framework}

Mathematics teachers in South Africa have different philosophical and ontological views on what mathematics teaching should encompass. This is especially true of how mathematics should be used, facilitated or taught in specific situations. Whilst many view mathematics teaching as conforming to a set of rules, others regard it as either a deductive or an inductive learning processes (Huetinck \& Munshin, 2000). Nieuwoudt (2006) recommends that the teaching and learning of mathematics should be viewed from an ontological-contextual perspective comprising six interrelated aspects: the teacher, learner, content, intention, live interaction and the context. These components collectively enable learners to perform learning tasks. Teachers, who facilitate teaching and learning, should have clear goals about what they want to achieve during teaching and learning interventions. Mathematics teachers ought to have the relevant mathematical knowledge, skills, attitudes and values that they want their learners to achieve in order to facilitate learners in a specific context (DOE, 2002).

With the introduction of ICT into teaching and learning, Mishra and Koehler (2006) built upon Shulman's theory and constructed the Technological Pedagogical Content Knowledge Conceptual Framework (TPCK), renamed by Schmidt et al. (2009) as TPACK, which describes the relationship between technology, pedagogy and content. In order for technology to add value to teaching and learning, it cannot be regarded as context-free, but must be linked to pedagogy. Figure 1 presents the TPACK framework with the seven components and shows the interface of the integration of content, pedagogy and technology.

Shulman (2004) discusses the categories of knowledge that facilitate teaching: content knowledge and pedagogical knowledge.

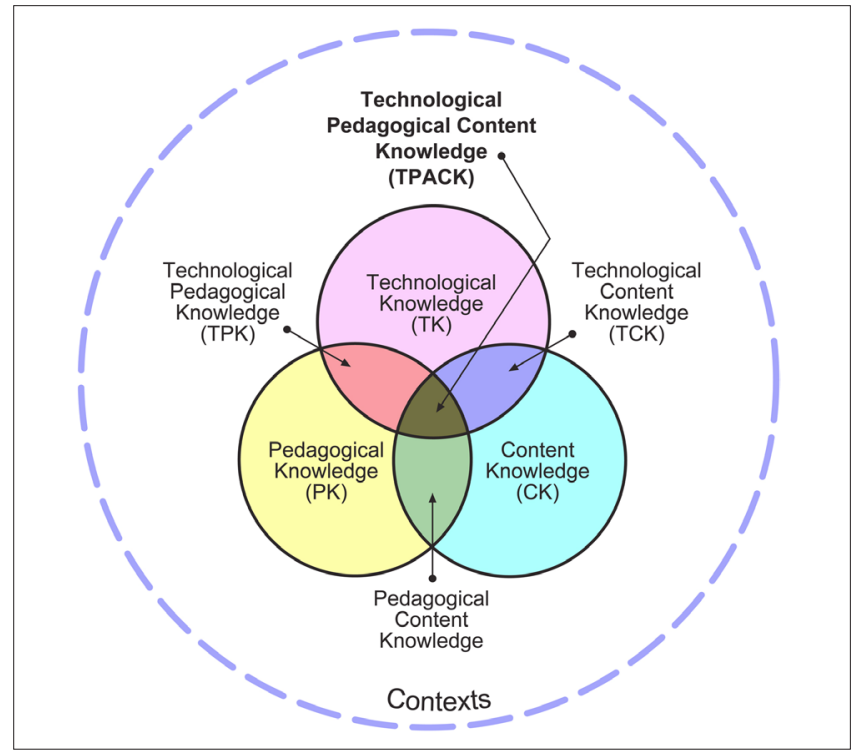

Source: Koehler, M.J. (2012). The seven components of TPACK. Available from http://www. matt-koehler.com/tpack/tpack-explained/

FIGURE 1: The Technological Pedagogical Content Knowledge (TPACK) conceptual framework.

Content knowledge refers to the quality and organisation of knowledge in the thought processes of teachers. Mathematics teachers should have appropriate content knowledge in order to be able to teach the subject fluently (Ball, Thames, \& Phelps, 2008; Mishra \& Koehler, 2006).

Pedagogical knowledge refers to the expertise of teachers in selecting appropriate methods of teaching the particular content to learners.

Pedagogical content knowledge, the interface between subject and pedagogical knowledge, is referred to as specialised content knowledge (Shulman, 2004). Pedagogical content knowledge becomes evident when teachers have the ability to build on their learners' prior knowledge and adapt their teaching strategies to best facilitate the new content to learners (Mishra \& Koehler, 2006). Content knowledge, pedagogical content knowledge and technological knowledge are important dimensions of effective teaching with ICT.

Technological knowledge refers to the ability and skills to use the variety of technologies such as books, chalk and blackboard, as well as technologies such as computers, the Internet and digital resources, to teach learners the required content.

Technological content knowledge refers to how content can be taught with the use of technology. Technological content knowledge is the area where technology and pedagogy link. This knowledge base is where the teaching and learning occur due to the existence, components and capabilities of the various technologies. Teachers with technological content knowledge select a specific teaching strategy, as well as the most appropriate ICT, to teach curriculum content to learners (Draper, 2010).

The central part of Figure 1 is the intersection between content knowledge, pedagogical knowledge and 
technological knowledge; this is known as Technological Pedagogical Content Knowledge (TPACK), which is not merely knowledge of technology, pedagogy and content individually, but also the basis of effective teaching with ICT (Koehler \& Mishra, 2009). TPACK aims to support skills development of teachers for acquiring and explaining how technology-related subject-specific knowledge is applied during teaching and learning activities (Koehler \& Mishra, 2009). Mathematics teachers are a diverse group with different teaching and learning styles; therefore, no single permutation of content, pedagogy and technology will be applicable to every teacher (Koehler, 2012). However, overall TPACK requires mathematics teachers to have:

- an understanding of how to represent mathematical concepts with technology

- pedagogical skills that utilise technologies constructively to transfer content

- fundamental knowledge of what brands mathematical concepts as difficult or easy to grasp

- knowledge of how technologies can assist learners in solving mathematical misconceptions

- knowledge of learners' existing mathematical knowledge and their learning styles

- knowledge of how to utilise technology to construct new knowledge using learners' existing knowledge (Koehler \& Mishra, 2009).

Learners can engage in an abundance of activities in which they utilise ICT; they can conduct research and communicate through ICT with peers and their teachers to augment their learning. ICT has the potential to enhance both the theoretical and practical aspects of teaching and learning: speeding up and enhancing work production, linking school curricula with reality, supporting exploration and experimentation, and providing immediate feedback. ICT focuses attention on overarching issues, increasing the relevance of underlying abstract objects to improve motivation and engagement (Osborne \& Hennessey, 2003). This, however, solely depends on how it is used by the teacher. More importantly, such activities will not be effective unless learners engage with technological devices. It is the teachers' responsibility to simultaneously impart ICT competency whilst focusing on mathematical pedagogical knowledge and developing learners' attitude and values in a constructivist learning environment (Draper, 2010; Galloway, 2007).

\section{Research design and methodology Secondary data analysis}

The study followed a methodology of secondary data analysis of the South African mathematics teachers' dataset of SITES 2006 (Brese \& Castens, 2009). Secondary data analysis refers to the empirical exercise that uses specific research questions and existing data for further analysis, using either the same or different statistical procedures (Smith, 2008). For t-tests and analysis of variance (ANOVA), the data consist of a set of scores, such as intelligence quotients, attitudes, time, errors and so on. Each subject has one quantitative score. For Chi-square $\left(\chi^{2}\right)$ analysis, however, the data are frequency counts in categories. Each subject is observed and placed into one category. The frequencies of observations in categories are counted and the Chi-square test is calculated from the frequency counts. Chi-square analysis compares the observed frequencies of a category to frequencies that will be expected if the null hypothesis is true (Spatz, 2008). In this case, statistical significance tests (e.g. Chi-square tests) are used to show that the results of the correlations between the items in the SITES 2006 mathematics teachers' questionnaire are practically statistically significant. Chi-square can be considered as effect sizes: A Cramér V value of less than 0.3 is considered to show a small effect with no or very little practically significant correlation; a Cramér V of between 0.3 and 0.4 is considered to signal a medium effect that tends towards practically significant correlation; a Cramér V value of 0.4 or larger is considered to show a large effect with practically significant correlation. The SITES 2006 dataset provided opportunities to explore the associations between variables that were not calculated or reported during the main study (Law et al., 2008).

\section{SITES 2006 South African mathematics dataset}

In the 1990s, the International Association for the Evaluation of Educational Achievement initiated comparative research on the use of ICT in education. SITES 2006 aimed to determine the influence of ICT on teaching and learning in schools (Blignaut, Els \& Howie, 2010). To date, three SITES studies (modules) have contributed to the understanding of how ICT affects the teaching and learning of mathematics and science in Grade 8 in schools across the world. SITES 2006 (Module 3), an international longitudinal comparative large-scale survey, investigated how school and system level factors influence teachers' pedagogical adoption of ICT (Law \& Chow, 2008a). In 2005, the 22 participating countries and education systems adapted, translated and piloted the survey instruments and trained their local project personnel and supplementary fieldworkers. Data collection took place during 2006 (Blignaut et al., 2010). SITES 2006 administered three questionnaires: (1) a questionnaire for school principals, (2) a questionnaire for ICT coordinators and (3) a questionnaire for mathematics and science teachers (Brese \& Castens, 2009).

Researchers from the University of Twente, Hong Kong University and the IEA Data Processing Centre in Hamburg, Germany, coordinated the main study. The national research coordinators of each country managed local data collection and data capturing (Law et al., 2008). The international study population comprised schools with learners enrolled for mathematics and science in the target grade, that is, schools with students studying in the grade that represents eight years of schooling (Blignaut et al., 2010). The sample size per education system was fixed at a minimum of 400 schools. In each school the teacher of one of the classes in the target grade (Grade 8 mathematics or science) was randomly selected to participate (Law et al., 2008). No official report was written of the SITES 2006 study for South Africa. This secondary data analysis focused on an aspect that was not 
analysed during the SITES 2006 study. The dataset used for this secondary data analysis comprised a stratified sample of the 640 mathematics teachers from about 500 randomly selected computer-using and non-computer-using schools who completed the SITES 2006 teachers' questionnaire (Blignaut et al., 2010). The second author of this study was the co-national research coordinator for SITES 2006 in South Africa and had access to the South African dataset.

\section{Procedures}

In order to address the research question, that is, to explore to what extent TPACK can contribute towards more effective Grade 8 mathematics teaching and learning in South African schools, the TPACK conceptual framework was applied. The SITES 2006 teachers' questionnaire comprised eight parts:

- Part I: Information on the target group

- Part II: Curriculum

- Part III: Teacher practice

- Part IV: Learner practice

- Part V: Learning resources and technology infrastructure

- Part VI: Impact of ICT use

- Part VII: Information about schools

- Part VIII: Specific pedagogical practices that use ICT

Associations were calculated between Item 21J (Part VIII) in the SITES 2006 teachers' questionnaire, I know which teaching or learning situations are suitable for ICT use (TPACK), and other variables from Parts II-VIII (available from Brese \& Castens, 2009) that focused on teaching and learning practices in Grade 8 mathematics classrooms. TPACK clusters (themes) were identified by the association study. Statistical relationships (associations) between categorical variables were determined with Chi-square tests and effect sizes to determine if the relationship was large enough to be significant (Ellis \& Steyn, 2003). Only the effect sizes of significance are reported. The Statistical Consultation Services of our university assisted in the cross tabulation analysis using SPSS® 16.0 for Windows (SPSS, 2007).

\section{Findings}

This section presents the findings that Grade 8 mathematics teachers who have TPACK 21J (I know which teaching or learning situations are suitable for ICT use) are more effective teaching mathematics in South African schools. The findings grouped into four clusters: (1) impact of ICT use, (2) teacher practices, (3) confidence and (4) barriers, according to the categories of the SITES 2006 questionnaire. Two categories are used to display the findings: percentages (TPACK and NO TPACK or Yes and No) and effect sizes (Figure 2).

\section{Technological pedagogical content knowledge clusters}

Figure 2 shows the effect sizes of the four main TPACK clusters. The following section will discuss these clusters.

\section{Impact of ICT use}

The main variable (21): I know which teaching or learning situations are suitable for ICT use) correlated with questions

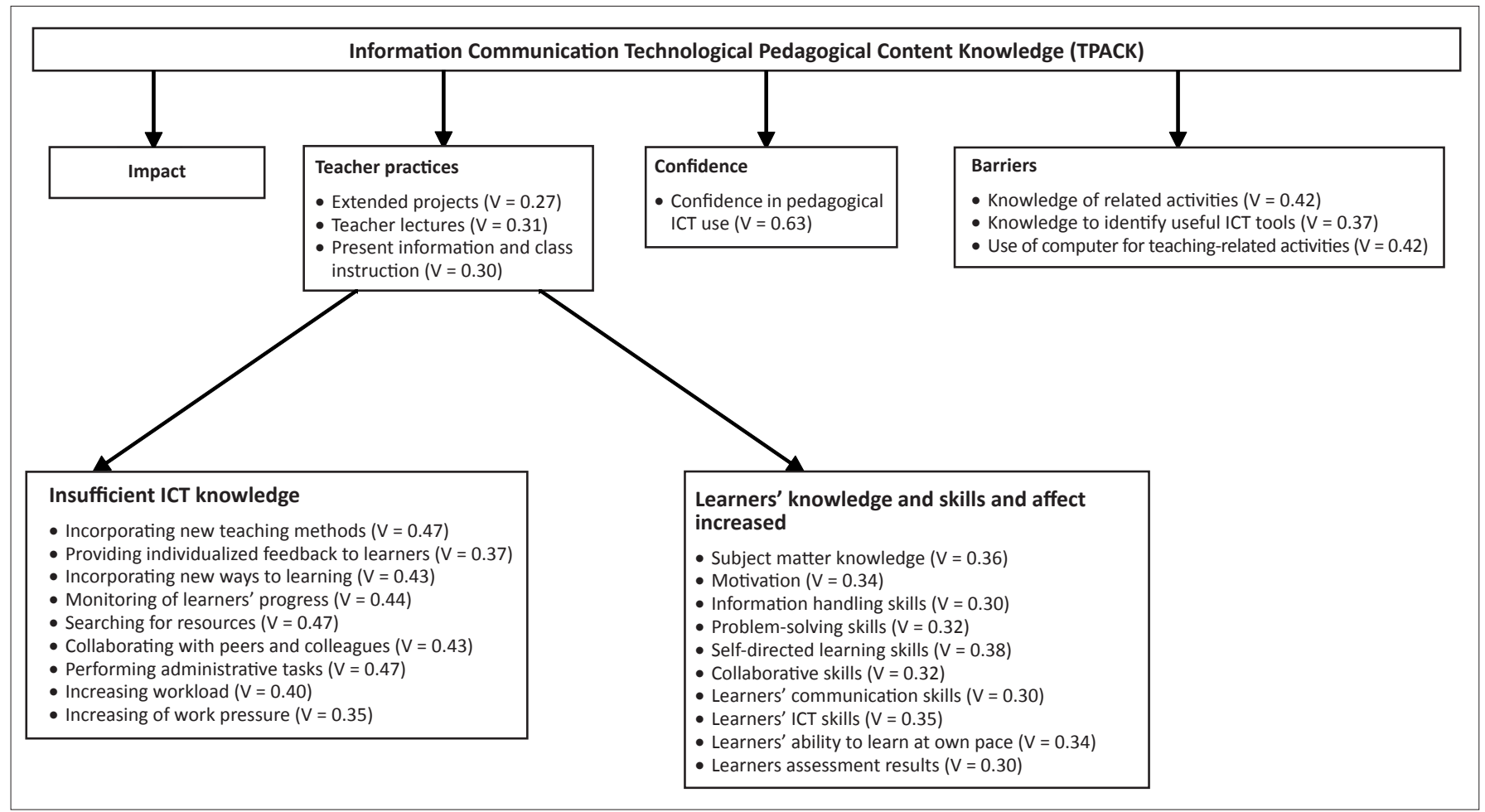

$V<0.3=$ small effect with no or very little practically significant association.

$0.3 \leq \mathrm{V} \leq 0.4=$ medium effect tending towards practically significant association.

$V \geq 0.4=$ large effect with practically significant association.

ICT, Information and Communication Technology.

Source: Cassim, V. (2010). The Pedagogical use of ICTS for teaching and learning within grade eight Mathematics in South African schools. Unpubished master's thesis. North-West University, Potchefstroom, South Africa. Available from http://dspace.nwu.ac.za/handle/10394/4487

FIGURE 2: Clusters (themes) identified through the associations between TPACK and other variables on the SITES 2006 teachers' questionnaire. 
19A-K from Part VI and items 20A-N from Part VII of the questionnaire; these items focused on the impact of ICT on different teaching, learning and planning aspects. For the purpose of this secondary data analysis, there was little difference between the three categories and the researcher combined the categories 'ICT knowledge to a certain extent (a little and somewhat)', 'adequate ICT knowledge (a lot)' and 'no knowledge to use ICT (not at all)' to create two analysis criteria: TPACK (I know in which teaching and learning situations to use ICT) and NO TPACK (I do not know in which teaching and learning situations to use ICT). The impact of TPACK clustered into two categories: (1) insufficient ICT knowledge by the teachers and (2) increase in learners' knowledge, skills and affect. These two categories correlated to a medium effect that tended towards a practically significant association and a large effect with practically significant association (Figure 2).

\section{Insufficient ICT knowledge}

Two hundred and twenty-two teachers responded affirmatively to the survey question 'I know which teaching and learning situations are suitable for ICT use'. The researchers posit that this portion of teachers represented the ideal population that had adequate and integrated technological, content and pedagogical knowledge (Figure 1), henceforth referred to as TPACK. Teachers who responded negatively to this question $(N=282)$ did not have all the elements of TPACK, but could relate to another category of the framework. In order to investigate which category of knowledge those non-TPACK teachers should improve, the responses to questions $19 \mathrm{~A}-\mathrm{K}$ were correlated with their responses to question 21J (Table 1).

Amongst the teachers who knew which teaching and learning situations were suitable for ICT use (TPACK in Table 1), 39\% did not think they had sufficient knowledge and skills to incorporate new teaching methods. Also, 61\% reported that they did not know in which situations to incorporate ICT, and also did not know when to incorporate new teaching methods (large effect, $\mathrm{V}=0.47$ ). Another large practically significant association ( $V=0.47$ ) was evident between TPACK and collaborating with peers and colleagues. Not knowing in which situations to use ICT, to a lesser extent though still with practical significance, correlated with absence of knowledge about searching for resources, incorporating new ways of learning and performing administrative tasks.
A portion of non-TPACK teachers found it difficult to provide individualised feedback; this correlation tended towards practical significance. This association could be due to insufficient ICT, subject or pedagogical knowledge (Thompson, 1988). A medium effect indicated the correlation between TPACK teachers and increased work pressure.

Overcrowded classrooms mean teachers are overworked. New or additional teaching requirements, without adequate training, make teachers less likely to embrace technology at their disposal for fear of increased work demands (Mofokeng \& Mji, 2009). These findings are in concurrence with the work of Al-Senaidi, Lin and Poirot (2009), who indicate that poor ICT knowledge leads to hindrances in the performance of teachers with insufficient TPACK. Although ICT was available to teachers in many cases, their TPACK did not seem to improve as there were other contributing factors preventing ICT integration. This suggests that although teachers may have access to computers, without adequate continuous professional teacher development, it is unlikely that ICT will be utilised optimally (Mofokeng \& Mji, 2009).

\section{Increase in learners' knowledge, skills and affect}

According to the TPACK framework, an ideal teacher is able to integrate knowledge of technology, mathematics, content and pedagogy (Figure 1), knows in which teaching and learning situations ICT use is suitable and has a positive effect on their learners' knowledge and skills. The questionnaire probed whether such knowledgable teachers reported whether such effects were observed in their learners. Three indicators were used: change, no impact and decrease in learners' knowledge, skills and effect. The correlations between the effect of the teachers' TPACK status and the change in their learners' knowledge and skills are given in Table 2 .

The teachers relating to this part of the analysis had TPACK. The analysis of this group of teachers yielded quite uniform results for all skills. Between $70 \%$ and $76 \%$ of these teachers indicated a change in the mathematics knowledge and skills in their learners since they started to implement ICT in teaching and learning, whilst $19 \%$ of those teachers indicated no impact. Less that $10 \%$ indicated a decrease in their learners' skills. It is not possible to pinpoint the reasons

TABLE 1: Correlations between teachers' with TPACK and teachers' knowledge and skills.

\begin{tabular}{|c|c|c|c|}
\hline ICT knowledge & v & TPACK $(\%)$ & No TPACK $(\%)$ \\
\hline Collaborating with peers and colleagues (19G) & 0.47 & 39 & 61 \\
\hline Incorporating new teaching methods (19B) & 0.47 & 46 & 54 \\
\hline Searching for resources (19F) & 0.44 & 38 & 62 \\
\hline Incorporating new ways of learning (19D) & 0.43 & 41 & 59 \\
\hline Performing administrative tasks (19l) & 0.43 & 42 & 58 \\
\hline Increase workload (19J) & 0.40 & 43 & 57 \\
\hline Individualised feedback (19C) & 0.37 & 43 & 57 \\
\hline Increase work pressure (19K) & 0.35 & 57 & 43 \\
\hline
\end{tabular}

$0.3 \leq \mathrm{V} \leq 0.4=$ medium effect tending towards practical significant association.

$V \geq 0.4$ = large effect with practically significant association

ICT, Information and Communication Technology; TPACK, Technological Pedagogical Content Knowledge. 
for the decrease of knowledge and skills amongst learners, as a number of factors can influence their learning. What is important is that all the mentioned skills in the learners increased in classes taught by TPACK teachers, with a medium association effect.

From these results it is evident that ICT, when integrated effectively into the curriculum, will pave the way for learners to achieve the critical and learning outcomes in mathematics (DOE, 2002).

\section{Teacher practices}

Mathematics teachers should embrace TPACK to deepen their teaching and learning experiences across the curriculum in order to ensure that the outcomes for mathematics are met (Mishra \& Koehler, 2006, p. 1026). TPACK is essential for ICT integration in mathematics classrooms and the use of ICT should form an integral part of teaching and learning practices. In order to investigate which category of teacher practices with ICT the non-TPACK teachers needed to focus on, the responses to questions 9A-C, 9G, 9H, 9J, 9M and 14A$\mathrm{L}$ from Part III were correlated with the responses to question 21J (Table 3).

Teacher practices with ICT of teachers with TPACK (Table 3) showed a medium associated effect. Many teachers (63\%) with no TPACK did not employ ICT during teaching, but some $(37 \%)$ tried to use ICT when teaching content to their learners. Teachers who had TPACK $(30 \%)$ were able to present essential information, provide rich demonstrations and facilitate interactive classes using ICT. TPACK enables teachers to build on their own, as well as their learners', existing knowledge in order to develop strong attitudes and positive beliefs towards mathematics (Mishra \& Koehler, 2006; Swan et al., 2002).

\section{Confidence}

Multiple studies on ICT integration have identified insufficient confidence as a major barrier to ICT integration in mathematics (Mofokeng \& Mji, 2009). With an increase in confidence, mathematics teachers become more enthusiastic, interested, motivated and committed to embracing ICT in their teaching and learning environment (Attwell \& Hughes, 2010; Uyangor \& Gör, 2010). The main variable (21J) was correlated with question 21I from Part VII, which focused on mathematics teachers' confidence in the pedagogical use of ICT; this correlation is shown in Table 4 .

A high practically significant association $(\mathrm{V}=0.63)$ was indicated between TPACK and mathematics teachers' confidence in preparing lessons that involved learners' use of ICT. The $8 \%$ of teachers who were confident to prepare lessons that involved ICT were those who had adequate TPACK to select the appropriate strategies and resources best suited to the teaching and learning of mathematics. The absence of confidence of the non-TPACK teachers prevented them from using ICT for mathematics teaching and learning. If teachers are meaningfully exposed to continuous professional teacher development in TPACK they will become confident to explore the vast array of ICT resources (Daly, Pachler \& Pelletier, 2010).

TABLE 2: Correlations between the effect of teachers' TPACK and status and the change the learners' increase in knowledge and skills.

\begin{tabular}{llcc}
\hline Teachers with TPACK & V & Change (\%) & No impact (\%) \\
\hline Self-directed learning skills (20E) & 0.38 & 74 & 28 \\
Subject matter knowledge (20A) & 0.36 & 74 & 19 \\
ICT skills (2OH) & 0.35 & 76 & 20 \\
Learning motivation (20B) & 0.34 & 74 & 7 \\
Learn at own pace (20I) & 0.34 & 74 & 23 \\
Collaborative skills (20F) & 0.32 & 71 & 22 \\
Problem-solving skills (20D) & 0.32 & 71 & 26 \\
Information handling skills (20C) & 0.30 & 74 & 25 \\
Communication skills (20G) & 0.30 & 75 & 23 \\
Assessment results (20N) & 0.30 & 70 & 3 \\
\hline
\end{tabular}

TPACK, Technological Pedagogical Content Knowledge; ICT, Information and Communication Technology.

TABLE 3: Correlations between teachers' TPACK and teacher practices with ICT.

\begin{tabular}{llc}
\hline Teacher practices with ICT & V & TPACK (\%) \\
\hline Teacher lectures (9G) & 0.31 & 37 \\
ICT present information in class instruction (14A) & 0.30 & 63 \\
Extended projects (9A) & 0.27 & 30 \\
\hline
\end{tabular}

$0.3 \leq \mathrm{V} \leq 0.4=$ medium effect tending towards practically significant association.

$V \geq 0.4=$ large effect with practically significant association.

$0.3 \leq \mathrm{V} \leq 0.4=$ medium effect tending towards practically significant association.

TPACK, Technological Pedagogical Content Knowledge; ICT, Information and Communication Technology.

TABLE 4: Correlations between teachers' TPACK and confidence to prepare lessons that involve the use of ICT.

\begin{tabular}{lccc}
\hline Teachers' confidence & V & NO TPACK (\%) & TPACK (\%) \\
\hline Lesson preparation that involve the use of ICT by learners (21I) & 0.63 & 8 \\
\hline
\end{tabular}




\section{Barriers}

The main variable (21J) was correlated with questions 23D, 23I and 30A from Part VII, which focused on the barriers to the use of ICT (Table 5). The respondents had the option to select from two categories (Yes or No). The non-TPACK mathematics teachers were requested to indicate whether they experienced barriers when using ICT during these activities. Figure 2 illustrates the items relating to barriers in using ICT.

A practically significant association $(\mathrm{V}=0.42)$ was evident between non-TPACK and the use of ICT for teaching-related activities. Mathematics teachers' inadequate use of ICT for teaching-related activities was a major barrier to TPACK. Identifying useful ICT tools $(\mathrm{V}=0.37)$ and ICT-related pedagogical skills $(\mathrm{V}=0.32)$ showed a medium associated effect. Non-TPACK teachers experienced difficulties in selecting appropriate useful ICT tools and they acknowledged their insufficient TPACK.

In order to address teachers' limited TPACK, it is essential for mathematics teachers to participate in training for the integration of ICT. Only $15 \%$ of the South African mathematics teachers participating in SITES 2006 had access to ICT training, $19 \%$ to technical training and 32\%to introductory courses (Law \& Chow, 2008a); even fewer had access to training on the integration of ICT in the curriculum (SchoolNet South Africa, 2008). Intel® Teach (Intel, 2012), a large teacher development program, identified one representative per school from 1000 schools across South Africa to attend ICT integration training. Their programme evaluation indicated that South African teachers demonstrated meagre ICT competencies, and that it would take at least five years to adequately train teachers to develop TPACK (Thomson \& Wilson-Strydom, 2005). However, none of these programmes were focused on developing mathematics teachers' ICT competencies. The majority of the mathematics teachers in the SITES 2006 study indicated that they wanted to prepare quality and interesting presentations and learning materials even though they had no ICT competencies (Law \& Chow, 2008b). The development of the teachers' TPACK would ensure ICT integration required by the e-Education White Paper (DOE, 2004). It becomes evident that the first and foremost responsibility of the Department of Basic Education (DBE) is continuous professional teacher development. If teachers receive appropriate professional development relating to ICT integration, ICT can become embedded in their pedagogical practices (Mishra \& Koehler, 2006). Teachers would have access to support in their preparation and facilitation (Howie \& Blignaut, 2009). They would better assist their learners to methods of problem solving, contribute towards the development of 21st century learning skills and achieve the outcomes for Grade 8 mathematics (DOE, 2002; Nieuwoudt \& Golightly, 2006).

Mathematics teachers are willing to integrate ICT despite inadequate TPACK. However, insufficient resources at schools impact on teachers' ability to create rich learning environments to stimulate learners' curiosity and interest in mathematics. It is disheartening that only $10 \%$ of schools had tutorial software and $35 \%$ had general software for the teaching and learning of mathematics (Law \& Chow, 2008b). In some provinces, only $1 \%$ of schools were connected to the Internet for teaching and learning purposes. The numbers of computers in school have increased dramatically since the first SITES study in 1999 (Pelgrum, 2001): 51\% of schools in 2007 throughout South Africa had computers at their disposal for curriculum activities (DOE, 2007). The DBE should address the social and economic disparities across the provinces and provide equal access to ICT to all schools in terms of ICT continuous professional development and ICT infrastructure. Even though the numbers have increased since SITES 2006, not all schools have equal ICT profiles, and not all achievement outcomes are on par with the aims of the White Paper on e-Education (DOE, 2004).

The White Paper on e-Education specifies that all managers and teachers should obtain access to personal computers to assist them during administrative tasks and during lesson preparation (DOE, 2004). In 2008 the DBE initiated the laptop-for-all initiative (Mahlong, 2012), aspiring to provide educators with laptops for the integration of teaching and learning, thereby improving the quality of education in, particularly, mathematics and science by 2011 . The laptopfor-all initiative never got off the ground. The initial criterion was the number of years in service of the DBE and only $11.43 \%$ teachers received laptops. Similarly to other DBE initiatives, this critical ICT initiative is two years behind schedule, with little hope for the fulfilment of its aims. In a report, it was announced that the teacher laptop initiative is alive again and that broader plans for ICT progression are in the making (Mahlong, 2012). However, no strategic plan is in place to support the initiative, and inadequate planning and insufficient resources discourage teachers to integrate ICT in their classrooms (Thomson \& Wilson-Strydom, 2005). In terms of the above findings, the professional development of teacher TPACK is challenged.

\section{Conclusions}

The research question that underpinned this secondary data analysis of the South African data of the SITES 2006 was to

TABLE 5: Correlations between non-TPACK teachers' and barriers in using ICT.

\begin{tabular}{lcc}
\hline Non-TPACK teachers' barriers & V & Yes (\%) \\
\hline Use ICT for teaching-related activities (30A) & 0.42 & 42 \\
Identifying useful ICT tools (23I) & 0.37 & 58 \\
ICT-related pedagogical skills (23D) & 0.32 & 28 \\
\hline
\end{tabular}


investigate the level of TPACK and to what extent TPACK of mathematics teachers contributes towards more effective Grade 8 mathematics teaching in South African schools. This study indicates that increases in TPACK of mathematics teachers, confidence in their ability to use ICT and levels of mathematical content knowledge will contribute towards more effective Grade 8 mathematics teaching in South African schools. The results indicate that mathematics teachers with adequate TPACK acknowledged that ICT had a positive impact: (1) they were able to access an abundance of resources for teaching and learning, (2) they could communicate with colleagues and peers regarding teaching and learning practices, (3) they became more innovative with their teaching and learning activities, (4) they could conduct all their administrative work, (5) they were able to facilitate interactive lessons and (6) they were confident using a variety of teaching and learning strategies best suited to achieve the outcomes of the curriculum. Raising the standard of mathematics education is a priority for the DBE (DBE, 2012). The DBE advocates that ICT interventions could address the shortcomings in the education system (Parliamentary Monitoring Group, 2011). The authors therefore advocate addressing and developing the TPACK and confidence of mathematics teachers. The DBE (2012) is looking for ICT solutions to address teacher training, professional development and provide complementary teaching and learning resources so as to improve the quality of classroom teaching. It is imperative that role players within the education system strengthen and support the DBE and work collaboratively to address backlogs in the system.

\section{Acknowledgements}

This work is based on research supported by the National Research Foundation of South Africa for the Second International Technology in Education Survey 2006 grant (ICD2006071400008) and the North-West University. The researchers wish to thank these institutions for the funding.

\section{Competing interests}

The authors declare that we have no financial or personal relationship(s) that might have inappropriately influenced us in writing this article.

\section{Authors' contributions}

V.L. (North-West University) was the main author of the article; A.S.B. (North-West University) was the project leader of the study; H.D.N. (North-West University) was the expert on mathematics issues; S.M.E. (North-West University) performed the statistical analysis; C.J.E. (North-West University) assisted in the interpretation of statistics.

\section{References}

Al-Senaidi, S., Lin, L., \& Poirot, J. (2009). Barriers to adopting technology for teaching and learning in Oman. Computers \& Education, 53(3), 575-590. http://dx.doi. org/10.1016/j.compedu.2009.03.015

Attwell, G., \& Hughes, J. (2010). Pedagogic approaches to using technology for learning: Literature review. Available from http://webarchive.nationalarchives. gov.uk/20110414152025/http:/www.lluk.org/wp-content/uploads/2011/01/ Pedagogical-appraches-for-using-technology-literature-review-january-11-FINAL. pdf
Ball, D. L., Thames, M.H., \& Phelps, G. (2008). Content knowledge for teaching: What makes it special? Journal of Teacher Education, 59(5), 389-407. http://dx.doi. org/10.1177/0022487108324554

Blignaut, A.S., Els, C., \& Howie, S. (2010). Contextualizing South Africa's participation in the SITES 2006 module. South African Journal of Education, 30(4), 555-570. Available from http://www.sajournalofeducation.co.za/index.php/saje/article/ Available from
view/242/216

Brese, F., \& Castens, R. (2009). Second Information Technology in Education Study: SITES 2006 user guide for the international database. Amsterdam: IEA Secretariat. Available from http://www.iea.nl/fileadmin/user_upload/Publications/Electronic versions/SITES_2006_IDB_User_Guide.pdf

Cassim, V. (2010). The pedagogical use of ICTs for teaching and learning within grade eight Mathematics in South African schools. Unpubished master's thesis. NorthWest University, Potchefstroom, South Africa. Available from http://dspace.nwu. ac.za/handle/10394/4487

Daly, C., Pachler, N., \& Pelletier, C. (2010). Continuing professional development in ICT for teachers: A literature review. London: Institute of Education, University of London. Available from http://eprints.ioe.ac.uk/3183/

Department of Basic Education (DBE). (2012, 17 May). Basic Education budget vote speech. National Assembly, Cape Town. Available from http://www.education. gov.za/Newsroom/Speeches/tabid/298/ctl/Details/mid/1929/ItemID/3334/ Default.aspx

Department of Education (DOE). (2002). National curriculum statement grades $R-9$ (Schools) Policy. Available from http://www.education.gov.za/LinkClick.aspx?filet icket=WJoXaOgvys $4 \% 3$ D \& tabid $=266 \&$ mid $=720$

Department of Education (DOE). (2004). White paper on e-Education: Transforming learning and teaching through information and communication technologies. Available from http://www.info.gov.za/whitepapers/2003/e-education.pdf

Department of Education (DOE). (2007). e-Learning in South Africa. Pretoria: Government Printer. Available from http://www.polity.org.za/article/pandorIdquoelearning-in-south-africardquo09012007-2007-01-09

Draper, K. (2010). Understanding science teachers' use and integration of ICT in a developing country context. Unpublished doctoral dissertation. University of Pretoria, Pretoria, South Africa.

Ellis, S., \& Steyn, H.S. (2003). Practical significance (effect sizes) versus or in combination with statistical significance ( $\mathrm{p}$-values). Management Dynamics, 12(4), 51-53.

Ertmer, P., Addison, P., Lane, M., Ross, E., \& Woods, D. (1999). Examining teachers' beliefs about the role of technology in the elementary classroom. Journal of Research on Computing in Education, 32(1), 54-72.

Galloway, J. (2007). Primary ICT for teaching assistance. (1st edn., Vol. 1). Glasgow: Routledge.

Haddad, W.D., \& Draxler, A. (2002). The dynamics of technologies for education. In D. Haddad, \& A. Draxler (Eds.), Technologies for education: Potentials, parameters and prospects (pp. 1-20). Washington, DC: Academy for Educational Development.

Howie, S.J., \& Blignaut, A. S. (2009). South Africa's readiness to integrate ICT into mathematics and science pedagogy in secondary schools. Education and Information Technology Journal, 14(1), 345-363. http://dx.doi.org/10.1007/ s10639-009-9105-0

Huetinck, L., \& Munshin, S.N. (2000). Teaching mathematics for the 21st century: Methods and activities for Grade 6-12. (2nd edn.). New Jersey, NJ: Pearson Education.

Intel. (2012). Intel ${ }^{\oplus}$ Teach Program Worldwide. Available from http://www.intel.com/ content/www/us/en/education/k12/intel-teach-ww.html

Koehler, M.J. (2012). The seven components of TPACK. Available from http://www. matt-koehler.com/tpack/tpack-explained/

Koehler, M.J., \& Mishra, P. (2009). What is technological pedagogical content knowledge? Contemporary Issues in Technology and Teacher Education, 9(1), $60-70$.

Law, N., \& Chow, A. (2008a). Pedagogical orientations in mathematics and science and the use of ICT. In N. Law, W.J. Pelgrum, \& T. Plomp (Eds.), Pedagogy and ICT use in schools around the world: Findings from the IEA SITES 2006 study (Vol. 23, pp. in schools around the world:
$122-179)$. Hong Kong: CERC.

Law, N., \& Chow, A. (2008b). Teacher characteristics, contextual factors and how these affect the pedagogical use of ICT. In N. Law, W.J. Pelgrum \& T. Plomp (Eds.),
Pedagogy and ICT use in schools around the world: Findings from the IEA SITES Pedagogy and ICT use in schools around the world:
2006 study (Vol. 23, pp. 182-223). Hong Kong: CERC.

Law, N., Pelgrum, W. J., Monseur, C., Brese, F., Carstens, R., Voogt, J., et al. (2008) Study design and methodology. In N. Law, W.J. Pelgrum, \& T. Plomp (Eds.), Pedagogy and ICT use in schools around the world: Findings from the IEA SITES 2006 study (Vol. 23, pp. 13-36). Hong Kong: CERC.

Mahlong, A. (2012). Teacher laptop initiative "back on track". Available from http:// saitnews.co.za/e-government/teacher-laptop-initiative-track/

Marais, D. (2009). ICT as an enabler for socio-economic development in South Africa. Unpublished MBA dissertation. University of Stellenbosch, Stellenbosch, South Africa.

McDonald, J. (1988). Integrating speadsheets into the mathematics curriculum. Mathematics Teacher, 81(8), 615-622.

Mishra, P., \& Koehler, M. J. (2006). Technological pedagogical content knowledge: A framework for teacher knowledge. Teacher College Record, 108(6), 1017-1054. http://dx.doi.org/10.1111/j.1467-9620.2006.00684.x 
Mofokeng, P., \& Mji, A. (2009). Teaching mathematics and science using computers: How prepared are South African teachers to do this? Procedia Social and Behavioral Sciences, 2(2010), 1610-1614.

Nieuwoudt, H.D. (2006). Approaches to the teaching and learning of mathematics: An interactive manual for mathematics education students and mathematics educators. Potchefstroom: North-West University.

Nieuwoudt, H.D., \& Golightly, A. (2006). Constructivism and teacher education: An integrated South African perspective. In B. De Muynck, \& H. Van der Walt (Eds.) A view on constructivism and education (pp. 107-131). Amsterdam: Buijten and Schipperheijn Publishing House.

Osborne, J., \& Hennessey, S. (2003). Literature review in science education and the role of ICT: Promise, problems and future decisions (Science, Trans.) (pp. 48) London: University of Cambridge. Available from http://hal.archives-ouvertes.fr/ docs/00/19/04/41/PDF/osborne-j-2003-r6.pdf

Parliamentary Monitoring Group. (2011). Mathematics and Science interventions: Departments of Basic and Higher Education, Science and Technology briefing. Available from http://www.pmg.org.za/report/20110914-department-basic education-focus-their-plans-addressing-low-rates-aca

Pelgrum, W.J. (2001). Infrastructure. In W.J. Pelgrum, \& R.E. Anderson (Eds.), ICT and the emerging paradigm for life-long learning: An IEA educational assessment of infrastructure, goals, and practices in twenty-six countries (2nd edn., pp. 119156). Amsterdam: IEA Secretariat.

Prew, M. (2013). SA's maths education crisis laid bare: Schools keep pass rates up by limiting subject choices, in the process sacrificing our poorest pupils' futures. Available from http://www.techcentral.co.za/sas-maths-education-crisis-laid bare/41806/
Schmidt, D.A., Baran, E., Thompson, A.D., Mishra, P., Koehler, M.J., \& Shin, T.S. (2009). Technological pedagogical content knowledge (TPACK): The development and validation of an assessment instrument for preservice teachers. Journal of Research on Technology in Education, 42(2), 123-149.

SchoolNet South Africa. (2008). Intel Teach Initiative. Available from http://www. schoolnet.org.za/atwork/intelttf.htm

Shulman, L. (2004). The wisdom of practice: Essays on teaching, learning, and learning to teach. San Francisco, CA: Jossey-Bass.

Smith, E. (2008). Using secondary data in education and social research. (2nd edn.). New York, NY: Bell and Bain Ltd.

Spatz, C. (2008). Basic statistics: Tales of distributions. Belmont, CA: Thomson Wadsworth

SPSS. (2007). SPSS ${ }^{\circledR} 16.0$ for Window, Release 16.0.0. Chicago, IL: SPSS Inc. Available from http://www.spss.com

Swan, K., Holmes, A., Vargas, J., Jennings, S., Meier, E., \& Rubenfield, L. (2002). Situated professional development and technology integration: The CATIE Mentoring Program. Journal of Technology and Teacher Education, 10(2), 169-190.

Thompson, A. (1988). Teachers' beliefs and conceptions: A synthesis of the research In D.A. Grouws (Ed.), Handbook on research on mathematics teaching and learning (pp. 136-145). New York, NY: McMillan.

Thomson, J., \& Wilson-Strydom, M. (2005). How has INTEL teach to the future worked in South Africa? Available from http://www.schoolnet.org.za/atwork/intelttf.htm

Uyangor, S. M., \& Gör, Ö. (2010). The attitudes of the prospective mathematics teachers towards instructional technologies and material developement course. The Turkish Online Journal of Educational Technology, 9(1), 213-220. 